\title{
The impact of hand hygiene in the primary care: to go beyond the hospital setting
}

\author{
I Devesa ${ }^{1 *}$, I Neves ${ }^{1,2}$, D Peres $^{1}$, F Vieira ${ }^{1}$, G Poças ${ }^{1,3}$ \\ From 3rd International Conference on Prevention and Infection Control (ICPIC 2015) \\ Geneva, Switzerland. 16-19 June 2015
}

\begin{abstract}
Introduction
Scientific evidence shows that hand hygiene is an easy and efficient practice in the reduction of healthcare associated infection, contributing to a decrease in morbidity and mortality. World Health Organization (WHO) "SAVE LIVES: Clean Your Hands" (SL-CYH) is still very centered in the hospital/ long term care settings.
\end{abstract}

\section{Objectives}

Adaptation of the WHO SL-CYH campaign to the primary care setting.

\section{Methods}

Implementation of the WHO multimodal methodology in a primary care setting involving 13 units, serving a population about 110.000 inhabitants. The implementation of the campaign was coordinated by the Infection Control and Antimicrobial Resistance Unit and focused on the following actions: (1) audits and correction measures to structural conditions of the units (for example: existence of alcohol-based handrub - ABHR- dispensers and washbasins to hand hygiene) and pocket ABHR available to the home care; (2) infection control link professionals observer training (replicated in each unit) and subsequent observational study before/after the campaign in 2013 and the year after (2014); (3) campaign launch event in each unit with distribution of promotional material (pens, pins, flyers, posters, small films, didactic games) and signature of formal commitment by the professionals; (4) celebration of Hand Hygiene Day ( 5 of May) with a walk for the general population and involving the local and national media; (5) organization of hand hygiene poster competition for professionals and (6) participation in the E-bug project directed to schools.

\section{Results}

Compliance rates on hand hygiene in the participating units was $56 \%, 82 \%$ and $82 \%$ before, after campaign in 2013 and 2014, respectively. The rate of compliance in the "first moment" was of $46 \%, 61 \%$ and $71 \%$ before, after campaign in 2013 and 2014, respectively.

\section{Conclusion}

The campaign methodology of WHO SL-CYH showed to be successful when applied to the primary care setting. The biggest difficulty was the inexistence of specific material in portuguese language and directed to this setting. The community intervention level seems to be an interesting contribution to WHO SL-CYH campaign.

\section{Disclosure of interest}

None declared.

\section{Authors' details}

${ }^{1}$ Infection Control and Antimicrobial Resistance Unit, Unidade Local de Saúde de Matosinhos, Matosinhos, Portugal. ${ }^{2}$ Infectious Diseases Unit, Unidade Local de Saúde de Matosinhos, Matosinhos, Portugal. ${ }^{3}$ Primary Care Unit, Unidade Local de Saúde de Matosinhos, Matosinhos, Portugal.

Published: 16 June 2015

doi:10.1186/2047-2994-4-S1-P161

Cite this article as: Devesa et al:: The impact of hand hygiene in the primary care: to go beyond the hospital setting. Antimicrobial Resistance and Infection Control 2015 4(Suppl 1):P161.

'Infection Control and Antimicrobial Resistance Unit, Unidade Local de

Saúde de Matosinhos, Matosinhos, Portugal

Full list of author information is available at the end of the article 